\title{
Pendampingan Pembuatan Produk Video Game Dengan Construct 3 pada Siswa Sekolah Tingkat Menengah Atas
}

\author{
Laurentius Kuncoro Probo Saputra ${ }^{\# 1}$, Danny Sebastian ${ }^{\sharp 2}$, Kristian Adi Nugraha ${ }^{\sharp 3}$, \\ Matahari Bhakti Nendya ${ }^{\sharp 4}$, I Kadek Dendy Senapartha ${ }^{\# 5}$

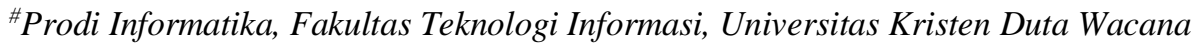 \\ Jl. Dr. Wahidin Sudirohusodo 5-25, Yogyakarta \\ ${ }^{1}$ kuncoro@staff.ukdw.ac.id \\ ${ }^{2}$ danny.sebastian@staff.ukdw.ac.id \\ 33adi.nugraha@staff.ukdw.ac.id \\ ${ }^{4}$ didanendya@staff.ukdw.ac.id \\ ${ }^{5}$ dendy.prtha@staff.ukdw.ac.id
}

\begin{abstract}
Abstrak - Situasi pandemi Covid-19 mengharuskan seluruh siswa sekolah melaksanakan pembelajaran secara daring. Suasana jenuh kerap dirasakan oleh siswa karena keterbatasan interaksi yang dapat mereka lakukan. Sebagai media untuk menghalau rasa jenuh, para siswa suka memainkan permainan video yang ada pada gawai mereka. Permainan video dapat memberikan hiburan sekaligus memiliki dampak yang baik untuk tingkat kreativitas dan logika berpikir seseorang. Perkembangan kreativitas dan logika dapat lebih terasah jika seseorang mampu merancang dan membuat game itu sendiri. Kegiatan pengabdian ini mengajak para siswa untuk dapat berproses dalam membuat video game sendiri. Pembuatan video game ini menggunakan game platform dari Construct 3. Peserta pendampingan berjumlah 5 orang berasal dari 3 SMA di Yogyakarta. Proses pendampingan dilakukan secara intensif selama 2 bulan. Hasil yang didapat dari pendampingan ini berupa 4 buah game yang berhasil dibuat oleh setiap peserta. Game yang dihasilkan juga telah diunggah pada layanan Google Play dan telah terdaftar pada karya cipta sebagai kekayaan intelektual. Hasil evaluasi kegiatan pendampingan ini memperlihatkan bahwa proses pembuatan permainan video dengan Construct 3 memberikan banyak manfaat bagi para siswa dalam hal pengembangan kreativitas dan logika berpikir mereka.
\end{abstract}

Kata kunci- permainan video, construct 3, pengembangan permainan video, siswa SMA.

Abstract - The Covid-19 pandemic situation requires all students to carry out online learning. The frustrating condition is often felt by students because of the limited physical interaction they can do with their friend. As a medium to dispel frustrating, students like to play video games on their devices.
Video games can provide entertainment as well as have a good impact on the their level of creativity and logic thinking. The improvement of creativity and logic thinking can be more honed if someone can design and create the game itself. This activity invited students to be able to develop their video game. This video game is developed using game platform development from Construct 3. The participants of this activity are 5 people from 3 high schools in Yogyakarta. The mentoring process was carried out intensely for 2 months. The results obtained from this assistance are in the form of $\mathbf{4}$ games that were successfully created by each participant. The resulting game has also been uploaded on Google Play services and has been registered in copyright as intellectual property. The evaluation results of this mentoring activity show that the process of making video games with Construct 3 provides many benefits for students in terms of developing their creativity and logical thinking.

Keywords - video game, construc 3, game development, senior high school student.

\section{PENDAHULUAN}

\section{A. Latar Belakang}

Keselarasan arah pendidikan antara Perguruan Tinggi dengan Sekolah Menengah Atas (SMA) harus dapat terwujud. Artinya kompetensi-komptensi dasar yang diberikan kepada para siswa SMA juga harus mampu membekali para siswa untuk melanjutkan studinya di berbagai bidang di tingkat Perguruan Tinggi. Berdasarkan panduan kurikulum SMA, mata pelajaran Informatika/ Teknologi Informasi diselenggarakan dalam kelompok 
mata pelajaran pilihan, dimana penyelenggaraannya dilakukan sesuai dengan kompetensi serta sarana dan prasaranan di satuan pendidikan. Sehingga melihat hal tersebut, tidak ada materi pembelajaran yang secara khusus dirancang untuk mempersiapkan kemampuan bidang informatika tingkat SMA. Hal ini mengharuskan pihak sekolah untuk bisa berimrovisasi untuk pengembangan materi pembelajaran bidang Informatika. Melihat hal tersebut, ada baiknya juga jika pihak Perguruan Tinggi turut serta memberikan masukan terkait meteri pembelajaran atau pengenalan pengetahuan-pengetahuan dasar dalam bidang Informatika.

Bersamaa dengan situasi pandemi Covid-19 yang masih belum memperlihatkan kapan berakhir, sehingga membuat proses pembelajaran secara daring masih harus terus dilakukan. Pihak sekolah melihat adanya peluang untuk dapat memanfaatkan momentum ini untuk dapat menyediakan pelatihan-pelatihan dan pembimbingan secara daring untuk meningkatkan kemampuan dan minat siswa di bidang Informatika. Berdasarkan keinginan tersebut, pihak sekolah juga menginginkan bentuk pelatihan dan pembimbingan bidang Informatika dengan topik-topik yang fun, tidak terlalu serius. Hal itu juga karena melihat bahwa para siswa sendiri terkadang sudah merasa jenuh untuk proses pembelajaran secara daring yang mengharuskan selalu berinteraksi komputer/ laptop. Sehingga perlu sebuah inovasi pembelajaran yang bersifat interkatif dan visual seperti sebuah video [1]. Seperti yang telah diterapkan oleh Roro Santi [2] dalam pengembangan media pembelajaran yang menarikn dan kreatif melalui sebuah video game untuk melatih membaca.

Melihat akan permasalahan dan kebutuhan tersebut, tim pengabdi Fakultas Teknologi Informasi Universitas Kristen Duta Wacana (FTI UKDW) bersama pihak sekolah menyepakati untuk dapat dilakukan proses tindak lanjut dari hasil kegiatan pelatihan pembuatan video game dengan Construct 3 yang telah dilakukan pada kegiatan pengabdian sebelumnya. Kegiatan pengabdian dalam bentuk pelatihan pembuatan video game yang sebelumnya pernah dilakukan melibatkan 3 sekolah tingkat SMA yaitu SMA Kolose De Britto, SMA Bopkri 1, dan SMA Pangudi Luhur Yogyakarta.

SMA Kolose De Brito menjadi salah satu mitra yang sangat membantu dalam terselenggaranya berbagai macam kegiatan pelatihan [3][4][5]. Melalui kemitraan dengan SMA Bopkri 1 juga terlaksana pelatihan multimedia [6],Sehingga kegiatan pengabdian yang dilakukan saat ini lebih berfokus pada pendampingan intensif kepada para siswa sehingga para siswa dapat menghasilkan produk video game secara murni dari hasil kreativitas dan proses pengembangan logika pemrograman.

Pengembangan video game sendiri dapat melatih imajinasi, kreatifitas, dan logika berpikiri yang terimplementasi dalam penyusunan logika permainan. Saat ini pengembangan video game tidak terbatas hanya pada seseorang di perguruan tinggi. Anak sekolah dasar pun sudah dilatih untuk mengembangkan sebuah game menggunakan Scratch [7]. Hal ini lah yang menjadikan pihak sekolah pun berkeinginan agar siswa-siswanya dapat didampingi dalam pengembangan sebuah produk video game pada tingkatan lanjut. Pendekatan pemrograman bagi anak sekolah tingkat menengah sangat terbantu dengan konsep pemrograman visual [8]. Selain itu, dengan pengenalan pengembangan video game, para siswa dapat mulai memahami beberapa aspek dari sebuah video game, yaitu game desain, game art, dan game mekanik [9]. Pengembangan sebuah game sangat membantu juga bagi para guru sebagai sebuah inovasi pendekatan pedagogic dalam penerapan ilmu dan pemahaman yang lebih nyata [10].

\section{B. Rumusan Masalah}

Kurikulum yang saat ini sedang digunakan oleh pendidikan tingkat SMA menempatkan mata pelajaran terkait teknologi komputer atau information technology (IT) sebagai mata pelajaran muatan lokal. Sehingga mata pelajaran tersebut bergantung oleh pihak sekolah bagaimana mengemas mata pelajaran IT akan diselenggarakan dalam bentuk dan materi seperti apa. Pihak sekolah dapat berinovasi terkait materi-materi yang akan diselenggarakan dalam mata pelajaran yang terkait dengan IT.

Melihat hal tersebut, akan sangat menjadi penting jika pihak sekolah juga bekerja sama dengan perguruan tinggi untuk merancang dan mengisi bersama terkait mata pelajaran IT. Hal ini dapat menjadi media untuk melakukan penyelarasan antara materi yang di tingkat SMA dengan kebutuhan kompetensi dasara yang dibutuhkan oleh lulusan SMA jika ingin melanjutkan studi di Perguruan Tinggi.

Kegiatan pengabdian ini akan berfokus pada permasalahan bagaimana materi atau pengetahuan terkait IT dapat diberikan kepada para siswa dalam bentuk kegiatan yang fun dan juga dapat menghasilkan produk hasil dari proses berpikir kreatif para siswa.

\section{Bentuk Kegiatan}

Berdasarkan permasalahan tersebut dan latar belakang yang ada, kegiatan pengabdian yand dilakukan bersama para mitra tidak hanya sebatas pendampingan intensif terhadap siswa untuk pengembangan produk video game menggunakan Construct 3 , tetapi mengajarkan juga kepada siswa untuk bisa menciptakan produk video game yang dapat dipublikasikan pada Google Play Store serta produk tersebut dapat dicatatkan dalam bentuk hak cipta pada pangkalan data Kekayaan Intelektual.

\section{Metode PelaksanaAn}


Kegiatan ini melibatkan siswa dari 3 sekolah tingkat SMA di Kota Yogyakarta, yaitu SMA Kolose De Britto, SMA Bopkri 1, dan SMA Pangudi Luhur. Total siswa yang mengikuti kegiatan pendampingan secara khusus ini sejumlah 5 orang. Pelaksana pendampingan dari FTI UKDW terdiri dari Danny Sebastian S.Kom., M.M., M.T., Kristian Adi Nugraha S.Kom., M.T., dan Lauretius Kuncoro Probo Saputra., S.T., M.Eng., Matahari Bhakti Nendya, S.Kom., M.T., dan I Kadek Dendy Senapartha, S.T., M.Eng. Selain pendamping dari FTI UKDW, setiap siswa juga didampingi oleh salah seorang guru dari masingmasing sekolah. Guru pendamping setiap siswa juga memiliki latar belakang pendidikan di bidang Teknologi Informasi (IT). Siswa SMA Kolose De Britto juga didampingi oleh ibu Megia Novita, S.T. Siswa SMA Bopkri 1 didampingi oleh bapak Bram Krisdiantoro, S.Kom. Siswa SMA Pangudi Luhur didampingi oleh bapak Joko Sugiono, S.Kom.

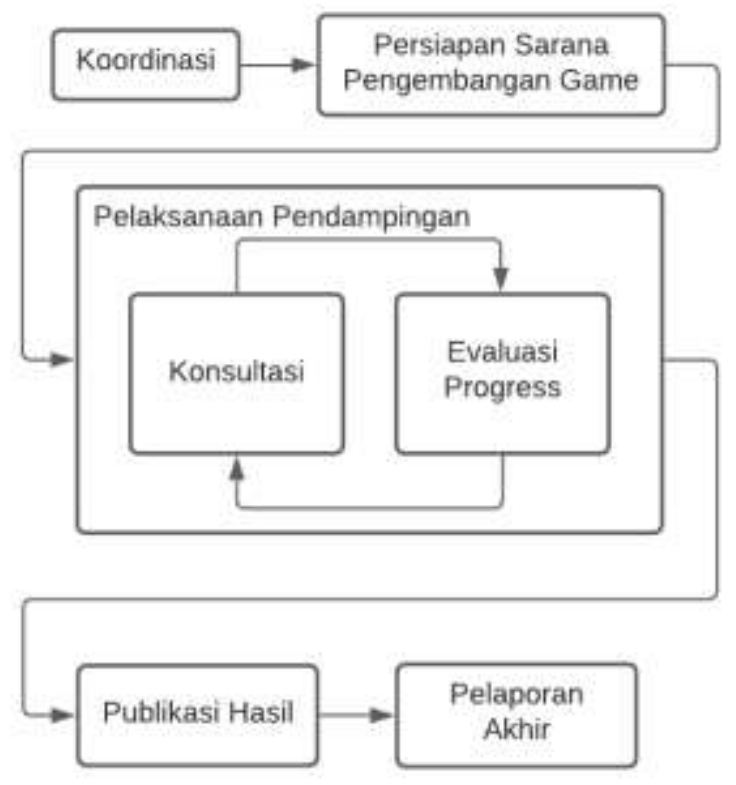

Gambar 3. Alur Kegiatan Pengabdian

Proses pendampingan secara intensif ini diharapkan setiap siswa mampu menghasilkan video game diakhir proses pendampingan. Secara umum kegiatan ini dilaksanakan dalam 5 tahap, yaitu koordinasi bersama siswa dan guru di setiap sekolah, proses persiapan aplikasi pengembangan game, pelaksanaan pendampingan, publikasi hasil pendampingan dalam bentuk video game, pelaporan akhir kegiatan. Alur tahapan kegiatan diperlihatkan seperti pada Gambar 3.

\section{A. Koordinasi Bersama Siswa dan Guru}

Pertemuan pertama bertujuan untuk melakukan koordinasi bersama siswa dan guru terkait rencana pelaksanaan kegiatan pendampingan khusus bagi siswa. Pada pertemuan ini, kami dari tim pengabdi FTI UKDW menginformasikan daftar siswa yang telah selesai melakukan pelatihan/ workshop pembuatan game di kegiatan pengabdian sebelumnya kepada para guru pendamping. Pada pertemuan ini juga, tim pengabdi memaparkan rencana untuk dapat dilakukan pendampingan lebih khusus lagi bagi siswa tersebut dalam kurun waktu 2 bulan (Mei - Juni 2021). Tujuannya ialah agar para siswa juga dapat menghasilkan video game hasil kreativitasnya sendiri. Rencana kegiatan tersebut juga didukung dengan waktu luang yang sedang dimiliki oleh para siswa, karena bertepatan dengan libur kenaikan kelas, yaitu di bulan Juni 2021. Pelaksanaan koordinasi ini dilakukan secara online menggunakan aplikasi Zoom.

\section{B. Persiapan Aplikasi Pengembangan Game}

Dalam proses pembuatan permainan video ini, para siswa akan menggunakan aplikasi pengembangan video permainan dari Construct 3. Pemilihan aplikasi Contruct 3 dirasa lebih mudah dipahami oleh siswa tangkat SMA untuk bisa membangun sebuah video permainan. Video permainan yang dihasilkan dari aplikasi Contruct 3 ini dapat dimainkan pada aplikasi browser atau perangkat smartphone Android. Supaya proses pengembangan tidak memiliki batasan dari fitur Construct 3, maka tim pengabdi berlangganan license Construct 3 selama 2 bulan untuk skema plan individual. Akun Construct 3 dengan plan individual ini dapat digunakan bersama-sama oleh seluruh siswa yang mengikuti kegiatan ini.

TABEL I

DAFTAR SISWA DAN DOSEN PEMBIMBING

\begin{tabular}{|l|l|l|l|}
\hline No & Nama Siswa & $\begin{array}{l}\text { Nama Dosen } \\
\text { Pembimbing }\end{array}$ & Asal Sekolah \\
\hline 1 & $\begin{array}{l}\text { Yohanes } \\
\text { Duns Scotus } \\
\text { Aerotri } \\
\text { Tunyanan }\end{array}$ & $\begin{array}{l}\text { I Kadek Dendy } \\
\text { Senapartha, } \\
\text { S.T., M.Eng. }\end{array}$ & $\begin{array}{l}\text { SMA Kolese } \\
\text { De Britto } \\
\text { Yogyakarta }\end{array}$ \\
\hline 2 & $\begin{array}{l}\text { Andre } \\
\text { Victory }\end{array}$ & $\begin{array}{l}\text { Danny Sebastian } \\
\text { S.Kom., M.M., } \\
\text { M.T. }\end{array}$ & $\begin{array}{l}\text { SMA } \\
\text { Pangudi } \\
\text { Luhur } \\
\text { Yogyakarta }\end{array}$ \\
\hline 3 & $\begin{array}{l}\text { Fransiskus } \\
\text { Adrianto } \\
\text { Setyawan }\end{array}$ & $\begin{array}{l}\text { Kristian Adi } \\
\text { Nugraha } \\
\text { S.Kom., M.T. }\end{array}$ & $\begin{array}{l}\text { SMA Kolese } \\
\text { De Britto } \\
\text { Yogyakarta }\end{array}$ \\
\hline 4 & $\begin{array}{l}\text { Gordon } \\
\text { Calcarine } \\
\text { Samosir }\end{array}$ & $\begin{array}{l}\text { Matahari Bhakti } \\
\text { Nendya, S.Kom. }\end{array}$ & $\begin{array}{l}\text { SMA Kolese } \\
\text { De Britto } \\
\text { Yogyakarta }\end{array}$ \\
\hline 5 & $\begin{array}{l}\text { Andreas } \\
\text { Anditya } \\
\text { Purnama }\end{array}$ & $\begin{array}{l}\text { Lauretius } \\
\text { Kuncoro Probo } \\
\text { Saputra., S.T., } \\
\text { M.Eng. }\end{array}$ & $\begin{array}{l}\text { SMA Bopkri } \\
\text { 1 Yogyakarta }\end{array}$ \\
\hline
\end{tabular}




\section{Pelaksanaan Pendampingan}

Pelaksanaan pendampingan dilakukan secara khusus bagi setiap siswa. Setiap siswa akan dibimbing oleh 1 orang dosen dari tim pengabdi FTI UKDW. Pembagian dosen pembimbing untuk setiap siswa seperti pada Tabel 1. Proses pendampingan langsung dari setiap dosen ini dilakukan untuk memastikan bahwa setiap siswa melakukan proses pengembangan video game ini dan siswa dapat melaporkan perkembangan proses pembuatan video game. Proses pendampingan dan komunikasi dengan setiap siswa dilakukan dengan menggunakan Whatsapp Group dan jika diperlukan berdiskusi langsung di Google Meet atau Zoom. Pelaksanaan pendampingan ini secara efektif mulai berjalan tanggal 1 Mei - 30 Juni 2021.

\section{Publikasi Hasil}

Target dari pendampingan pengembangan video game ini ialah siswa dapat membuat video game yang nantinya dapat didaftarkan hak cipta di DirJen Kekayaan Intelektual serta video game tersebut dapat dipublikasikan di Google Play. Oleh karena itu, untuk memenuhi target tersebut para siswa harus membuat seluruh konten media seperti gambar, suara, dan logika programmnya sendiri. Untuk publikasi di Google Play, setiap siswa akan mengubah format file hasil video game mereka sehingga video game yang dibuat dapat dijalankan pada smartphone Android, dan dapat diizinkan untuk dipublish di Google Play.

\section{E. Pelaporan Akhir Kegiatan dan Evaluasi}

Rangkaian proses kegiatan ini diakhiri dengan melakukan evaluasi dan pembuatan laporan secara menyeluruh. Evaluasi dilakukan untuk melihat kualitas hasil proses pendampingan ini, baik dari sisi siswa maupun para dosen dan guru pendamping. Evaluasi dilakukan terhadap siswa dengan menggunakan formular kuesioner dalam bentuk Google Form. Proses pelaporan hasil kegiatan ini digunakan sebagai bahan evaluasi bentuk kegiatan pengabdian serta untuk melihat peluang kelanjutan dari kegiatan yang telah dilaksanakan.

\section{HASIL DAN EvaLUASI PELAKSANAAN}

\section{A. Hasil Pelaksanaan}

Proses pendampingan telah dilakukan selama 2 bulan, terhitung 1 Mei hingga 30 Juni 2021. Proses pendampingan dilakukan secara intens untuk memastikan hasil video game yang dibuat oleh siswa sesuai dengan target yang direncanakan di tahap awal. Pelaksanaan pendampingan memiliki jadwal untuk melaporkan perkembangan pembuatan video game setiap 1 minggu sekali. Untuk menjaga agar siswa tetap melakukan dan melaporkan hasil pembuatan game, tim pengabdi FTI UKDW juga selalu berkomunikasi dengan guru pendamping dari asal sekolah siswa. Guru pendamping juga akan membantu untuk memantau perkembangan pembuatan oleh siswa.

Proses monitoring dilakukan dengan berbagai media, seperti komunikasi melalui whatsapp group yang telah dibuat, seperti Gambar 2. Pemantauan perkembangan dan konsultasi melalui whatsapp group digunakan untuk berkomunikasi atau konsultasi singkat. Selain itu juga, pemantauan dan konsultasi juga disediakan dalam media Zoom untuk mengakomodasi jika ada permasalahan teknis dalam pengembangan video game yang membutuhkan penjelasan dan tutorial secara detail. Seperti pada Gambar 3, Bapak Matahari Bhakti Nendya dan tim pengabdi sedang memberikan pengarahan penyelesaian teknis yang sedang dihadapi oleh siswa dalam sesi monitoring dan konsultasi online via Zoom.

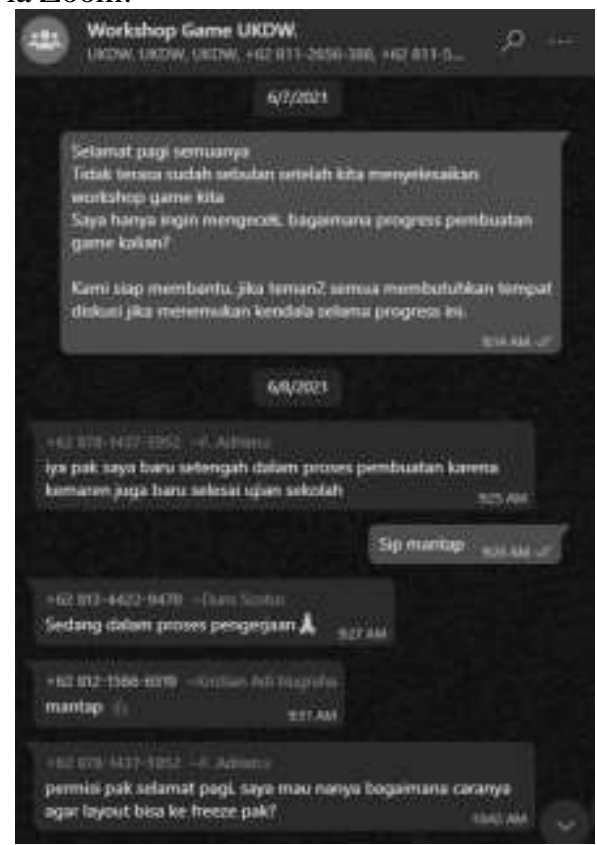

Gambar 4. Proses Monitoring Perkembangan Pembuatan Video Game dengan Whtasapp Group

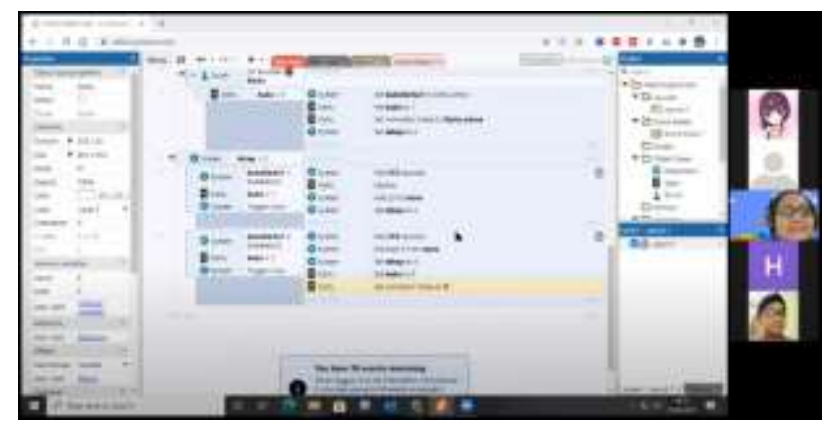

Gambar 5. Konsultasi Teknis Constract 3 dengan Aplikasi Zoom 
Dari 5 orang siswa yang mengikuti pendampingan khusus pembuatan video game ini, seluruhnya berhasil membuat sebuah game sederhana. Tetapi hanya 4 orang yang bersedia untuk diajukan untuk pencatatan Hak Cipta. Empat orang siswa tersebut berasal dari SMA BOPKRI 1 dan SMA Kolose De Britto. Berikut 4 buah game yang berhasil dibuat dalam proses pendampingan

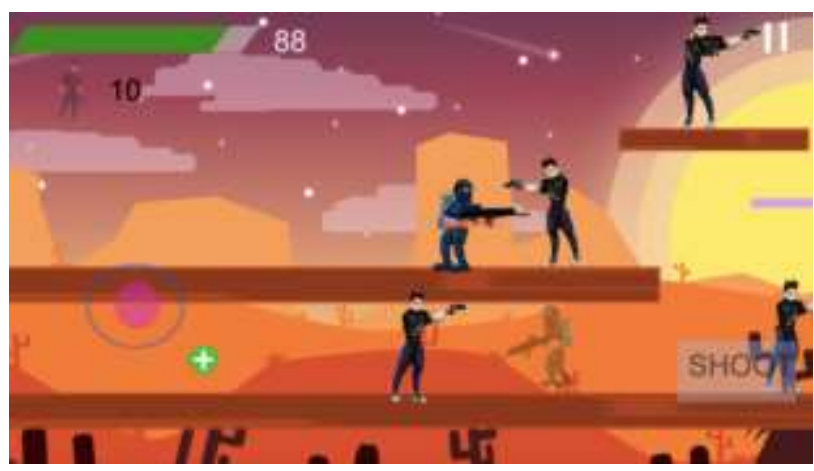

Gambar 6. Produk Game 1 - Arena Shooting

Gambar 6 merupakan video game yang dihasilkan oleh Gordon Calcarine Samosir dari SMA Kolose De Britto. Game ini menceritakan tentang Tony, seorang ilmuan yang ingin melawan kelompok cyber-teroris yang sudah mengambil baju zirah miliknya. Zirah tersebut memiliki kemampuan tahan panas dan juga anti peluru yang jika jatuh ke tangan yang salah akan membuat dunia ini dikuasai oleh orang yang memiliki zirah tersebut. Tony berusaha untuk mengambil kembali zirah yang sudah dicuri itu dalam rangka untuk menyelamatkan dunia.

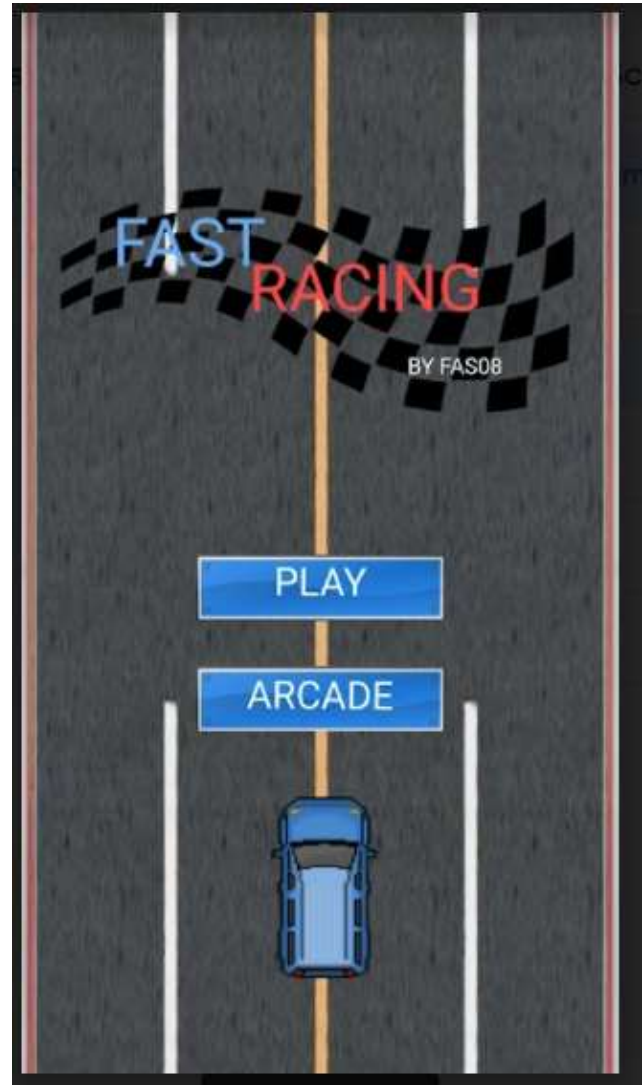

Gambar 7. Produk Game 2 - Fast Racing (1)

Gambar 7 merupakan video game yang dihasilkan oleh Fransiskus Adrianto Setyawan dari sekolah SMA Kolose De Britto. Video game ini mengharuskan pemain dapat mengendarai mobil sambil menghindari rintangan yang ada. Semakin lama pemain bertahan, maka skor yang didapatkan akan semakin tinggi. Apabila pemain menabrak rintangan atau mobil keluar dari jalur, maka permainan akan selesai. Rintangan yang harus dihindari oleh mobil seperti pada Gambar 8 . 


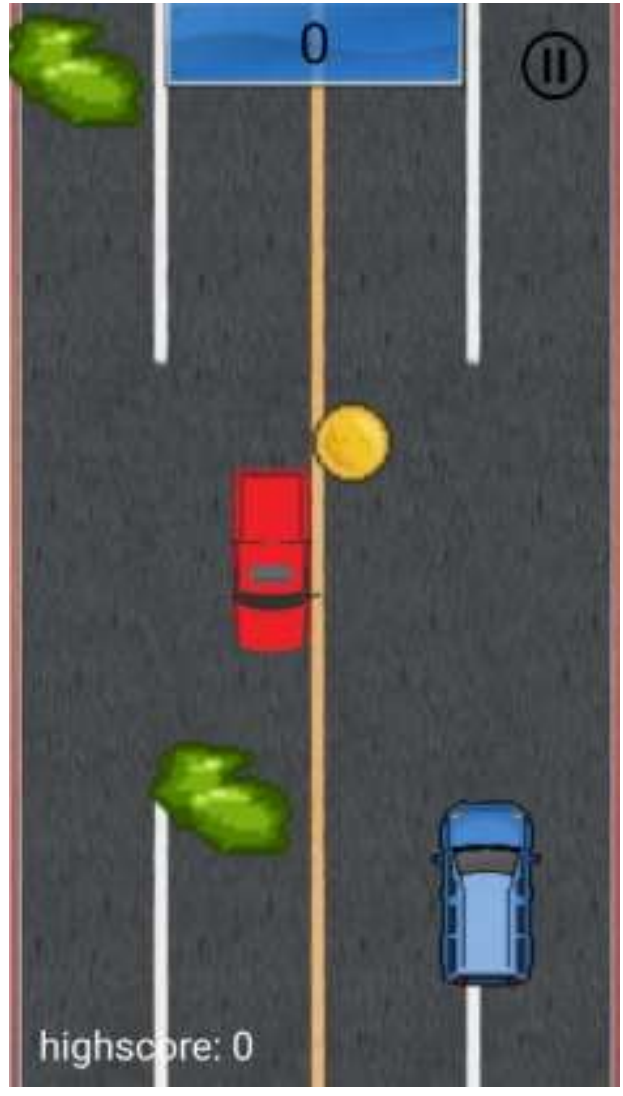

Gambar 8. Produk Game 3 - Fast Racing (2)

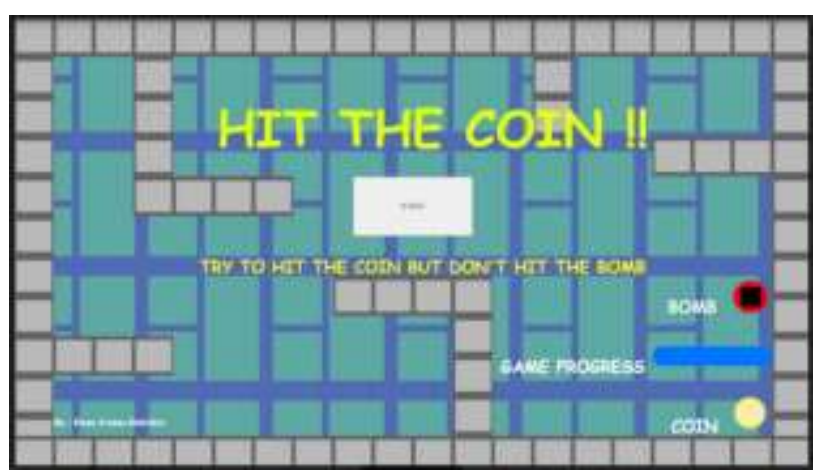

Gambar 9. Produk Game 3 - Hit The Coin

Gambar 9 menampilkan video game yang merupakan permainan teka teki dengan cara mencari jalan terbaik untuk mendapatkan koin. Saat petualangan pencarian koin dijalankan, pemain harus melewati jebakan atau rintangan yang menantang, terbagi pada 4 level dengan tingkat kesulitan yang berbeda. Untuk dapat menyelesaikan permainan, pemain harus dapat melewati semua level tersebut. Video game ini dihasilkan oleh siswa SMA Kolose De Britto bernama Yohanes Duns Scotus.

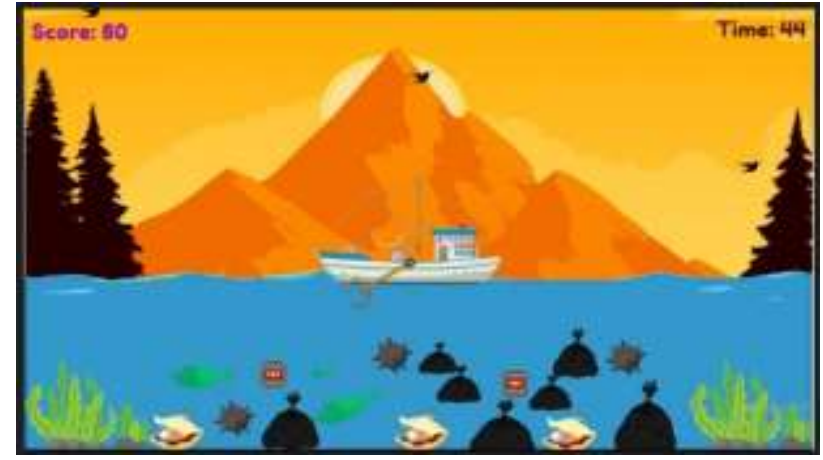

Gambar 10. Produk Game 4 - Ocean Garbage Rush

Gambar 10 merupakan produk game dengan judul Ocean Garbage Rush yang telah dihasilkan oleh Andreas Anditya Purnama dari sekolah SMA Bopkri 1. Game ini berlatar belakang kehidupan di lautan. Peran kita dalam memainkan game ini adalah mengambil sampah-sampah yang ada di lautan. Permainan ini juga untuk membujuk seseorang untuk menjaga kebersihan kehidupan laut dengan cara yang asik. Cara memainkan game ini yaitu dengan cara klik sembarang tempat untuk menurunkan kail. Kail tersebut ditepatkan pada sampah untuk mendapatkan poin. Hindari bom agar point tidak berkurang.

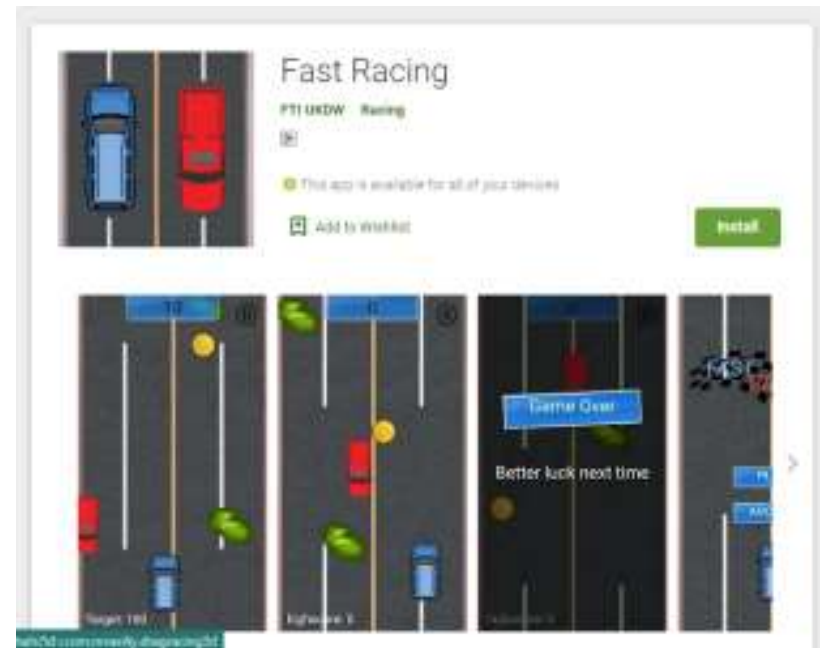

Gambar 11. Fast Racing di Google Play

Game yang berhasil dibuat, selain dicatatkan dalam 4 buah Hak Cipta Kekayaan Intelektual, game tersebut juga didampingi untuk dapat lulus standar dan dipublikasikan di Platform Google Play dengan akun Google FTI UKDW sebagai publisher-nya. Gambar 11 memperlihatkan hasil produk video game yang terpublish di Google Play Store.

\section{B. Evaluasi Pelaksanaan}


Secara umum, kegiatan pendampingan intensif pengembangan produk video game ini telah dapat berjalan dengan baik. Ada beberapa poin evaluasi dalam bentuk kuesioner yang dapat menjadi bahan evaluasi dari tim pengabdi terkait kegiatan yang telah dilakukan. Poin-poin evaluasi yang dibuat untuk menilai umpan balik dari siswa terkait proses pendampingan ini dalam bentuk penilaian terhadap diri siswa sendiri dan penilaian terhadap tim pelaksana kegiatan pendampingan. Poin-poin yang menjadi evaluasi terkait dengan siswa yaitu:

1) Siswa mengalami peningkatan pemahaman terkait pengembangan produk game dengan Construct 3: 4 dari 5 siswa yang mengikuti pendampingan intensif ini sangat setuju bahwa mereka mendapatkan peningkatan pemahaman terkait penggunaan Construct 3 sebagai alat untuk mengembangkan produk video game. Nilai kuesioner untuk poin ini 4,8/5.

2) Siswa tidak membutuhkan waktu yang lama untuk mengembangkan produk game: Rata-rata nilai kuesioner terhadap poin ini ialah 3,2/5. Dari nilai ini dapat dilihat, siswa masih tetap membutuhkan waktu untuk dapat menciptakan video game walaupun sebelumnya para siswa sudah pernah mendapatkan pelatihan pengembangan video game dengan Construct 3. Tetapi para siswa pun dapat menyesuaikan proses pengembangan video sesuai waktu yang diberikan. Sehingga siswa dapat berhasil mengumpulkan video game yang mereka buat tepat waktu.

3) Motivasi untuk menjadi game developer: Nilai kuesioner untuk poin evaluasi ini sebesar 4/5. Dari sini dapat dilihat bahwa para siswa memiliki motivasi yang sejalan dengan proses pendampingan ini. Para siswa sudah berkeinginan untuk menjadi game developer, sehingga mereka dengan maksimal ingin membuat game ini.

4) Siswa masih memerlukan bantuan dalam bentuk konsultasi dan sumber-sumber di internet karena siswa masih merasa kurang mampu memahami bagaimana sebuah alur permainan game diimplementasikan: Pada poin evaluasi ini, para siswa setuju dengan nilai kuesioner sebesar 3,8/5. Hal ini terlihat dari proses konsultasi yang begitu banyak diisi dengan pertanyaan-pertanyaan dari para siswa saat proses pendampingan berlangsung.

5) Kepuasan terhadap hasil video game yang tercipta: Para siswa menilai bahwa mereka puas terhadap hasil video game yang mereka buat. Nilai kuesioner pada poin ini sebesar 3,8/5.

6) Kegiatan pendampingan intensif ini membantu para siswa untuk pengembangan kompetensi dalam bidang IT: Para siswa memberikan nilai rata-rata untuk poin evaluasi ini sebesar 4,8/5. Nilai kuesioner yang didapat menandakan bahwa para siswa merasakan mendapatkan pengetahuan dan pemahaman di bidang IT salah satunya dalam game development.

Poin evaluasi lainnya yang dibuat untuk menilai proses penyelenggaraan kegiatan pendampingan ini, ialah:

1) Dosen pendamping memberikan penyampaian yang mudah saat siswa memiliki permasalahan dalam proses pembuatan video game: Siswa memberikan nilai rata-rata sebesar 4.4/5.

2) Dosen pendamping membantu dalam proses memahami bagaimana proses logika permainan diimplementasi pada Construct 3: Siswa memberikan nilai rata-rata sebesar 4,8/5.

Berdasarkan nilai yang didapatkan pada poin evaluasi bagi dosen pendamping dapat disimpulkan bahwa dukungan dosen pendampinga sangat membantu para siswa dalam penyelesaian pengembangan produk video game ini.

\section{Kesimpulan}

Kesimpulan yang dapat diambil dari kegiatan ini ialah para siswa mampu mengembangkan kreativitasnya dan logika berpikir untuk dapat mengimplementasikan pola permainan dalam bentuk pengembangan video game menggunakan Construct 3. Walaupun siswa sebelumnya telah mendapatkan pelatihan terkait pengembangan video game dengan Construct 3, siswa tetap merasa perlu untuk dapat didampingi dalam membuat video game yang sepenuhnya bersumber dari kreativitasnya. Sehingga pada akhirnya setiap siswa dapat menghasilkan video game yang mampu dipublikasikan pada Google Play Store.

\section{UCAPAN TERIMA KASIH}

Penulis mengucapkan terima kasih kepada Universitas Kristen Duta Wacana melalui Lembaga Penelitian dan Pengabdian Masyarakat (LPPM) yang sudah membiayai kegiatan pengabdian ini. Terima kasih juga diucapkan kepada SMA Kolose De Britto, SMA Bopkri 1, dan SMA Pangudi Luhur yang juga telah mendukung sebagai mitra dalam kegiatan pengabdian ini.

\section{DAFTAR PUSTAKA}

[1] B. B. Wahyujati, "PENINGKATAN KEMAMPUAN GURU SEKOLAH DASAR MELALUI PELATIHAN PEMBUATAN MEDIA VIDEO PEMBELAJARAN INTERAKTIF MENGGUNAKAN MS POWER POINT Bertha," ABDIMAS ALTRUIS J. Pengabdi. Kpd. Masy., vol. 4, no. Oktober, pp. 94 99, 2021.

R. Santi, "Multimedia Learning Dengan Game Engine Construct 2 (Game Bubble Click Untuk Latihan Membaca)," Tematik, vol. 7, no. 1, pp. 89-107, 2020. 
[3] D. Sebastian, K. A. Nugraha, and L. K. P. Saputra, "Webinar dan Workshop Pengenalan Internet of Things (IOT) untuk siswa SMA Kolese De Britto," Patria J. Pengabdi. Kpd. Masy., vol. 3, no. 2, p. 87, Sep. 2021.

[4] W. S. Raharjo, D. Sebastian, A. R. Chrismanto, and L. K. P. Saputra, "Pemanfaatan G Suite for Education untuk Meningkatkan Efektivitas Belajar Mengajar dan Kapasitas Guru SMA," Pros. Semin. Nas. Hasul Pengabdi. Kpd. Masy., vol. 4, no. November, pp. 100-105, 2019.

[5] Rini, M. N., Sebastian, D., and K. A. Nugraha, "Pelatihan Competitive Programming Tingkat SMA untuk Siswa Kelas XII SMA Kolese De Brittole," in Seminar Nasional hasil Pengabdian kepada Masyarakat (SENDIMAS), 2019.

[6] A. Wibowo and H. B. Santoso, "Peningkatan Kapasitas Siswa SMA Bopkri 1 Yogyakarta di Bidang Multimedia," Semin. Nas. Has. Pengabdi. Kpd. Masy., vol. 3, no. 1, pp. 53-58, 2018.

[7] A. Deuis, F. Ramadhan, and T. Widodo, "Pelatihan Programming Junior Pembuatan Game Menggunakan Scratch untuk Sekolah Dasar ( SD ) Sebagai Upaya Kesiapan Menghadapi Industri Kreatif,” J. Pemberdaya. Masy. Berkarakter, vol. 3, no. 2, pp. 111-120, 2020.

[8] D. Topalli and N. E. Cagiltay, "Improving programming skills in engineering education through problem-based game projects with Scratch," Comput. Educ., vol. 120, pp. 64-74, 2018.

[9] M. B. Nendya, S. Gandang, R. G. Santosa, J. T. Elekto, and F. T. Industri, "Pemetaan Perilaku Non-Playable Character Pada Permainan Berbasis Role Playing Game Menggunakan Metode Finite State Machine," J. Animat. Games Stud., vol. 1, no. 2, pp. 185-202, 2015.

[10] S. Hayhow, E. A. Parn, D. J. Edwards, M. R. Hosseini, and C. Aigbavboa, "Construct-it: A board game to enhance built environment students' understanding of the property life cycle," Ind. High. Educ., vol. 33, no. 3, pp. 186-197, 2019. 